\title{
Segmentação de palavras e poesia infantil: notas sobre ensino de ortografia nos anos iniciais do ensino fundamental
}

DOl: http://dx.doi.org/10.21165/el.v49i3.2728

\section{Giovanna Alves ${ }^{1}$ \\ Luciani Tenani $^{2}$}

\section{Resumo}

Neste artigo, investigamos possibilidade de ensino de ortografia nos anos iniciais do Ensino Fundamental a partir de poemas infantis selecionados da obra Ou Isto ou Aquilo de Cecília Meireles. O arcabouço teórico se embasa em uma concepção de escrita heterogênea. Analisamos segmentações não convencionais de palavras, como "que ria" (para "queria"), identificadas nos textos produzidos antes e depois de aula sobre os poemas de Cecília Meireles. Esse trabalho favoreceu a reflexão sobre segmentações alternativas de palavras, como "aponta" > "a ponta" e a construção de sentidos dos versos a partir de possibilidades de segmentação de palavras. Argumentamos, a partir de resultados obtidos por meio de análises quanti e qualitativa, que o trabalho sobre ortografia de palavra a partir de poemas infantis contribui para que crianças possam identificar fronteiras de palavras ortográficas e refletir acerca de sentidos de enunciados escritos.

Palavras-chave: segmentação de palavras; poesia infantil; aquisição da escrita; ortografia; prosódia.

\footnotetext{
1 Universidade Estadual Paulista (UNESP), São José do Rio Preto, São Paulo, Brasil; alvess.giovanna@gmail.com; https://orcid.org/0000-0001-5146-5981

2 Universidade Estadual Paulista (UNESP), São José do Rio Preto, São Paulo, Brasil; luciani.tenani@unesp.br; https://orcid.org/0000-0002-8487-0825
} 


\title{
Word segmentation and children poetry: notes about teaching word spelling in the initial years of Elementary School
}

\begin{abstract}
In this paper, we investigated the possibility of teaching word spelling from selected poems of Cecilia Meireles "Ou Isto ou Aquilo", in the early years of elementary school. The theoretical framework is based on a conception of heterogeneous writing. We analyzed unconventional word segmentations, such as "que ria" for "queria" (wanted), identified in children's texts produced before and after the class about Cecilia Meireles's poems. This work contributed to the reflection on alternative word segmentations, such as "aponta" ([it] points) > "a ponta" (the tip), and the construction of meanings of the verses related to the possibilities of word segmentations. Based on results obtained from quantitative and qualitative analysis, we argued that working with word notion from the poems contributes so that the children can identify the written word boundaries and reflecting on the meanings of written utterances.
\end{abstract}

Keywords: word segmentation; children poetry; writing acquisition; orthography; prosody.

\section{Introdução}

Neste artigo, temos como propósito tratar da possibilidade de ensino da palavra ortográfica nos anos iniciais do Ensino Fundamental (EF), a partir do trabalho com textos poéticos infantis da obra Ou isto ou Aquilo, de Cecília Meireles. O conjunto de poemas infantis selecionados tem a característica comum de haver segmentações alternativas de palavras, isto é, cadeias fônicas passíveis de identificação de diferentes fronteiras de palavras, como em "a ponta" > "aponta" e "sacada" > "sacada". A questão que formulamos é: em que medida o trabalho com textos poéticos infantis que apresentam segmentações alternativas de palavras favorece a reflexão e o aprendizado sobre limites gráficos de palavras pelas crianças em processo de aquisição da escrita?

Para encontrarmos a resposta, investigamos ocorrências de segmentações não convencionais de palavras, como "que ria" (queria), "asveze" (as vezes) e "ou vifala" (ouvi falar), em produções textuais de 39 crianças, à época da coleta, com idade entre oito e nove anos, que frequentavam a rede pública do município de São José do Rio Preto/SP e estavam matriculadas no terceiro ano do EF. Foram coletados um total de 78 textos, metade produzida antes e a outra metade depois da realização de atividades com poemas infantis. Esse material foi analisado visando caracterizar o processo de segmentar palavras por crianças expostas a um trabalho de reflexão sobre a ortografia da língua portuguesa a partir de textos poéticos. 
De modo específıco, buscamos analisar quantitativamente ocorrências de segmentações não convencionais de palavra, comparando as grafias antes e após o trabalho realizado em sala de aula com as crianças. Qualitativamente, as ocorrências foram analisadas quanto à sua estrutura prosódica de modo a identificar possíveis correlações entre configuração métrica de segmentações alternativas de palavras, encontradas nos poemas, e configuração métrica de segmentações não convencionais de palavras, encontradas nos textos das crianças. A partir dos resultados obtidos, argumentaremos ser significativo o trabalho com textos poéticos infantis em sala de aula para o ensino de fronteira de palavra ortográfica a crianças que se encontram em aquisição da escrita. Nossa argumentação está baseada na consideração de indícios identificados nas produções infantis, como traços e apagamentos, assumidos, nesse estudo, como marcas do trabalho das crianças, enquanto sujeitos da linguagem, com as fronteiras das palavras e, principalmente, com os possíveis sentidos dos enunciados escritos.

\section{Fundamentação teórica: “Pois escrever é difícil, não é criança?”}

As segmentações não convencionais de palavras são grafias cujos limites de palavra, seja por meio do espaço em branco, seja por meio do sinal gráfico hífen (TENANI, 2016), são registrados de modo diferente do que está previsto pela convenção ortográfica. Neste artigo, consideraremos dados apenas em que há registros não convencionais do espaço em branco. As segmentações serão classificadas em três tipos, a saber: (i) hipersegmentação, quando há presença não convencional do espaço em branco dentro de palavra, como "em vapora" para "evapora"; (ii) hipossegmentação, quando há ausência do espaço em branco entre palavras, como "alapisera" para "a lapiseira" e (iii) híbrido (CUNHA, 2010) ou mescla (CHACON, 2004), quando há presença e ausência não convencional do espaço em branco em uma sequência de palavras, como "ou todia" para "outro dia".

Essa classificação advém de um esforço trilhado por linguistas como Abaurre e Cagliari (1985), Abaurre (1988, 1989, 1991), Abaurre e Silva (1993), que, desde a década de 1980, têm interesse em descrever características da escrita infantil, tendo em consideração a organização de aspectos fônicos da linguagem, notadamente, aspectos rítmicos e entoacionais. Os registros de fronteiras de palavras são especialmente instigantes porque, ao não seguirem as convenções ortográficas, revelam regularidades dos enunciados falados, cujas unidades não coincidem com as unidades gráficas.

O advento das chamadas teorias não-lineares que tratam do componente fonológico da língua permitiu novas perspectivas quanto à organização da fala, notadamente no que diz respeito à abordagem fonológica da prosódica de diferentes línguas. Valendo-se do arcabouço da Fonologia Prosódica (NESPOR; VOGEL, 1986), Capristano $(2004,2007)$, Chacon $(2004,2005)$ e Cunha (2010), para citar apenas alguns, buscam explicitar a complexidade linguística que se deixa entrever por meio dos registros da escrita inicial 
infantil. Este artigo filia-se a esta abordagem que lança mão das bases da Fonologia Prosódica para embasar, metodologicamente, a identificação de constituintes prosódicos como unidades linguísticas que subjazem às grafias de palavras que não seguem as convenções ortográficas.

De modo mais específico, assumimos, junto com Capristano $(2004,2007)$ e Chacon (2004, 2005), que segmentações não convencionais de palavras são: (i) hipóteses dos escreventes acerca dos limites de palavras escritas, (ii) indícios de organização prosódica e rítmica da língua. Ainda com esses autores, destacamos que a relação entre fala e escrita é aspecto central para interpretação dos dados de escrita infantil. Essa relação não é de interferência de uma modalidade falada na modalidade escrita, mas constitutiva, como propõe Corrêa (2004). De acordo com esse autor, fala e escrita são modos de enunciação que se constituem por práticas sociais orais e letradas. Corrêa (2004, p. 9) conceitua o modo heterogêneo de constituição da escrita como "o encontro entre as práticas sociais do oral/falado e do letrado/escrito, considerada a dialogia com o já falado/escrito e ouvido/lido".

A partir dessa perspectiva, que não compreende fala e escrita como modalidades puras, interpretaremos as segmentações não convencionais de palavras como evidências de que características da fala são constitutivas da escrita e interpretaremos esses dados linguísticos como eventos privilegiados para a investigação da escrita de crianças. Sendo assim, as grafias produzidas pelos escreventes que não coincidem com aquelas ditadas pelas convenções ortográficas serão interpretadas como pistas do funcionamento e da natureza heterogênea constitutiva da escrita.

A concepção da escrita como constituída pela fala está embasada na consideração da complexidade enunciativa na língua. Essa complexidade também se revela por meio das segmentações alternativas de palavras, implicando a ambiguidade de interpretação dos enunciados, como o enunciado escrito "acorda, amor" que alternativamente pode ser falado/lido como "a corda, amor". Na comparação entre os enunciados, a palavra "acorda", forma flexionada (no presente do indicado e terceira pessoa do singular) do verbo "acordar", pode ser segmentada como "a corda", uma sequência de artigo "a" e substantivo "corda".

Na descrição da natureza dos textos poéticos usados no desenvolvimento de atividades pedagógicas, consideraremos versos que se caracterizam por mais de uma possível fronteira de palavra e, por conseguinte, por mobilizar mais de um sentido. Nesses casos, tem-se uma segmentação alternativa de palavra. Em outras palavras, segmentação alternativa de palavras é aqui definida quando diferentes interpretações de sentidos são possíveis a uma cadeia fônica a depender de como são estabelecidos os limites de palavras no enunciado. A segmentação alternativa de uma cadeia fônica implica a veiculação de, no mínimo, dois sentidos e/ou ambiguidade do enunciado, como "aponta" 
e "a ponta". Tenani (2001) argumenta a favor da natureza heterogênea da estrutura da linguagem, notadamente explicitando aspectos da estrutura prosódica identificados em textos chistosos e faz uso das segmentações alternativas para evidenciar a ambiguidade constitutiva da língua, sistema heterogêneo. Neste artigo, valemo-nos de textos poéticos de Cecília Meireles selecionados por possuírem versos em que segmentações alternativas são passíveis de identificação, favorecendo o trabalho com possibilidades de identificação de palavras a partir de uma cadeia fônica, como argumentaremos ao longo deste artigo.

Por fim, devemos explicitar que os poemas que selecionamos podem ser textos privilegiados para que crianças reflitam sobre a ortografia da língua portuguesa. Zilberman (2005, p. 130), ao discorrer sobre poesia infantil, ressalta que no texto poético trabalha-se na "perspectiva da diversão, do jogo e da brincadeira". De acordo com Abramovich (1997, p. 67), "a poesia não é mais do que uma brincadeira com as palavras" e "nessa brincadeira, cada palavra pode e deve significar mais de uma coisa ao mesmo tempo". Meireles joga com a ludicidade sonora, verbal, gráfica e, na atividade de juntar e separar palavras, expõe diferentes significados de uma mesma palavra, ou diferentes segmentos que, a depender de como são dispostos, revelam novos sentidos. Na poesia infanto-juvenil de Cecília Meireles, esses jogos lúdicos com palavras fazem render fantasia, sensibilidade, imaginação e diversão (MARQUEZI, 2000).

Acrescenta-se que os poemas de Cecília Meireles favorecem descobertas de sentidos do texto, jogos lúdicos com palavras e, esses, por sua vez, envolvem mecanismos de segmentações, rimas, aliterações, assonâncias, explorando a relação entre o fônico e o gráfico. Entendemos que o poema explora a complexidade enunciativa da linguagem de modo lúdico, divertido. Lidar com essa complexidade enunciativa da linguagem é fundamental para criança em processo de alfabetização, como procuraremos demonstrar nas próximas seções.

\section{Material e questões metodológicas: "Este é o meu jardim”}

O material da pesquisa é composto por 78 textos produzidos por 39 crianças - à época, com idades entre oito e nove anos - que frequentavam o terceiro ano do ensino fundamental em duas escolas da rede pública do município de São José do Rio Preto (SP). A escolha das escolas foi feita pela Secretaria Municipal de Educação que usou do critério de haver necessidade de apoio pedagógico da universidade às turmas definidas. Participaram 72 crianças das atividades, tendo sido incluídas nesta pesquisa 39 delas, independentemente da escola a que se vinculavam. O critério de inclusão das crianças foram os de haver dois textos por criança a fim de ser possível a comparação entre eles quanto às grafias de palavras. 
Para que pudéssemos propiciar às crianças momento de reflexão sobre fronteiras de palavras, selecionamos um conjunto de quatro poemas que apresentava segmentações alternativas de palavras: "Tanta tinta", "O eco", "Na sacada da casa" e "A folha na floresta". A partir desses textos poéticos, elaboramos atividades de leitura, escrita e análise linguística. Os materiais apresentados às crianças eram compostos por: proposta textual, slides e vídeo com poema recitado, ilustrado e animado.

Para planejamento das atividades que foram aplicadas em ambiente escolar, recorremos a documentos oficiais de orientações para o ensino de língua portuguesa. Buscamos orientações no caderno "A oralidade, a leitura e a escrita no Ciclo de Alfabetização" do Pacto Nacional de Alfabetização na Idade Certa (BRASIL, 2015). Nesse caderno, tomamos como base, especialmente, as orientações apresentadas no texto de Ludmila Andrade, professora e pesquisadora que adota uma concepção de escrita que vai ao encontro da assumida nesta pesquisa, isto é, a escrita como modo de enunciação da língua, heterogeneamente constituída por práticas sociais orais e letradas.

A proposta de produção textual foi elaborada com base na temática do poema "O Eco". Durante a atividade em sala de aula, apresentamos o poema escrito, para que os alunos fizessem leitura, e as orientações para a produção textual. Propomos a produção de um texto narrativo por meio do qual os alunos, como a personagem do poema "O Eco", fariam relato de suas dúvidas e curiosidades.

O vídeo, por sua vez, foi desenvolvido com áudio do poema declamado sincronizado aos versos escritos e às ilustrações animadas no Laboratório de Fonética - LabFon - do Instituto de Biociências e Ciências Exatas (IBILCE), câmpus da UNESP³. Desse modo elaborado, o vídeo permitiu que as crianças pudessem ler e ouvir ao mesmo tempo o texto poético. Esse vídeo constitui um material que favorece o trabalho de reflexão sobre o que foi lido e ouvido/falado, aspecto que nos interessa assegurar visando investigar as relações entre fala e escrita.

Esse material foi elaborado com base no gênero poesia. Essa escolha se deu por haver, de nossa perspectiva, o caráter indissociável entre práticas sociais letradas/escritas e práticas sociais orais/faladas, tendo em conta os recursos de assonância, rima, ritmo, por exemplo, e prática letrada que mobiliza, ao mesmo tempo, a prática de ler (ou ouvir a leitura do) o poema 4 .

3 Contamos com a colaboração do professor Dr. Ulisses Infante, para declamar o poema; de Amanda Gatto, para ilustrar o poema; do técnico de recursos audiovisuais Rômulo Borim, para produzir o vídeo.

4 Em texto inédito, Komesu e Tenani (2018), a partir de análise de painéis acadêmicos, discutem relações entre linguagem verbal e não verbal e tratam de práticas de escrita que, além de lidas, necessitam ser ouvidas/faladas à luz de uma concepção de escrita heterogeneamente constituída (CORRÊA, 2004). 
Também elaboramos uma série de slides, intitulada "Brincando com palavras", que foi apresentada às crianças visando aproximá-las do aspecto lúdico da (língua)gem, explorado por Meireles nos poemas. Recorremos a recursos como cores das letras e figuras de objetos referidos nos poemas. Por meio desses recursos, procuramos expor efeitos de sentidos resultantes das possibilidades de segmentação de uma mesma cadeia fônica de versos dos poemas selecionados. Nos slides, apresentamos os poemas na íntegra e destacamos versos que, em especial, possibilitariam abordar critérios de segmentação de palavras adotados pela ortografia do português.

Expostos os materiais elaborados para desenvolvimento do estudo em questão, passamos à caracterização das circunstâncias que cercaram as atividades desenvolvidas.

Os 78 textos do material são organizados em dois grupos, sendo o primeiro constituído de uma produção inicial de cada criança, antes do trabalho com poemas, e uma reescrita da produção inicial, após a realização das atividades propostas. O critério de seleção dos textos foi haver, seja na escrita inicial ou na reescrita, grafias cujo limites das palavras não estavam de acordo com a convenção ortográfica da língua portuguesa. Esse critério foi adotado para atender ao objetivo da pesquisa de, ao comparar a escrita inicial e a reescrita de cada sujeito, encontrar indícios da reflexão epilinguística realizada antes e depois de terem sido exploradas, a partir do texto poético, possibilidades de segmentação de palavras e relação entre fala e escrita.

Na primeira oficina, às crianças foi apresentado o texto poético "O Eco" (em folha impressa) que foi lido e comentado coletivamente. Após a leitura do poema e a interpretação coletiva dos sentidos do poema pelas crianças, fizemos a leitura da proposta textual e da temática relacionada ao poema lido, seguida da exposição das orientações com relação à produção dos textos que consistiam, especificamente, em: (i) tema, (ii) modo de usar a folha destinada à elaboração do texto (Papel A4 com linhas impressas e margens delimitadas) e (iii) material de escrita. As condições de produção dos textos estavam de acordo com as práticas adotadas pelas instituições escolares, de modo que as crianças não apresentaram resistência ou dificuldades no desenvolvimento da atividade. Nessa etapa, houve 72 escritas iniciais no total.

Na segunda oficina, fomos à sala de aula com projetor de vídeo e lousa digital e, na primeira parte do horário da aula, apresentamos o vídeo e os slides elaborados. Ambas as escolas dispunham dos equipamentos necessários para essa segunda oficina. Nessa oficina, iniciamos as atividades com a exibição do vídeo no qual havia poema declamado e ilustrações animadas. A partir do vídeo, discutimos o que tinha sido ouvido/falado e lido e como se dava a relação entre o que ouvimos/falamos e escrevemos. Nesse momento, exploramos, por exemplo, o ritmo do poema a partir de alguns versos que foram exibidos. Essa atividade se embasou nos estudos de Abaurre (1989), Tenani (2016), Silva (2014) que, ao investigarem relações entre segmentação de palavras e fonologia, apontaram que 
crianças segmentam palavras nos limites de pés métricos, muitas vezes, de estrutura trocaica, ou seja, com base na relação de proeminência forte e fraca entre as sílabas, a mais recorrente no português. Levamos as crianças a refletirem sobre "sons" que se sobressaiam ou que se mostravam proeminentes, de modo a observar as sílabas tônicas das palavras. Buscamos explorar a relação entre ritmo e limites de palavras, justificando que a proeminência de uma sílaba em relação a outra(s) não é critério suficiente para registro de fronteiras de palavras ${ }^{5}$.

Após exibição do vídeo e discussão da relação entre fala escrita e entre o lido e o ouvido, passamos às leituras de versos de outros poemas ${ }^{6}$. Buscamos atribuir um caráter lúdico à atividade por meio de desenvolvimento de brincadeira com palavras, cujo objetivo foi encontrar as palavras escondidas dentro de outras palavras. Essa proposta foi inspirada nas palavras de Authier-Revuz (1998), que trata de palavras sob palavras, e nas reflexões de Capristano (2007) e Chacon (2005), que lançam mão de haver uma hipótese interpretativa da segmentação de palavras feita pelas crianças que vislumbram possibilidades de identificação de palavras da língua "dentro" de outras palavras, como exemplificamos nos versos a seguir. Em (1), "aponta" está contida em "desaponta"; em (2), "embarco" está contida em "desembarco". Nos exemplos, são destacadas em itálico as palavras-alvo e são sublinhadas as sílabas passíveis de serem reconhecidas como monossílabos do português.

(1) A ponte aponta

e se desạponta

(2) Com desembaraço

embarco e

desembarco

Esse jogo de descoberta de palavras nos versos do poema foi trabalhado com as crianças. Ao término da exibição do vídeo e dos slides, convidamos as crianças a fazerem análise de sua escrita ${ }^{7}$, seguida da reescrita de seus textos iniciais. Desse modo, favorecemos a reflexão sobre os espaços em branco que delimitam palavras ortográfıcas nas produções escritas.

5 Esclarecemos que, nas oficinas, não foram utilizadas terminologias específicas. A utilização dos recursos verbo-visuais tinha por intenção, justamente, tornar o mais visual (e concreto) possível as informações sobre palavras para as crianças.

6 Apresentamos a autora dos poemas e as condições de produção dos poemas que seriam trabalhados com as crianças.

7 Neste artigo, "análise" pelas crianças compreende a atividade de reler seu próprio texto, podendo reformular o que fosse necessário, da ótica da criança. As marcas gráficas desse trabalho de revisão realizado pelas crianças não será objeto de consideração neste artigo. Registramos que essas marcas ocorreram e serão objeto de análise de pesquisa em curso. 
Nessa segunda oficina, foram produzidos outros 72 textos, como na primeira oficina. Contudo, somente 39 dessa segunda produção compõem o material ora analisado junto com 39 escritas iniciais, tendo em conta o critério ocorrência de segmentações não convencionais de palavras nas duas produções. Nesses textos selecionados, identificamos o total de 143 dados de segmentações não convencionais de palavras, sendo 94 dados identificados nas produções iniciais e 49 nas reescritas.

Na próxima seção, descrevemos características das grafias de palavras quanto à ausência do branco em fronteira de palavras e à presença do branco dentro de palavra, comparando essas grafias em relação à primeira e à segunda produção coletadas.

\section{Análise e discussão: regularidades e particularidades no processo de grafar palavras}

Nas análises que se seguem, expomos resultados quantitativos e qualitativos, sendo os quantitativos obtidos a partir de teste de estatística descritiva. Na descrição qualitativa, identificamos as estruturas prosódicas mobilizadas nas segmentações não convencionais de palavras, sempre comparando as escritas iniciais às reescritas produzidas pelas crianças.

\section{"E todos aprenderam a falar noite e dia a mesma melodia": análises das regularidades dos aspectos gráficos da escrita de palavras}

Para realizar as análises quantitativas, tomamos a decisão, baseados no estudo de Tenani (2016), de trabalhar com índices de segmentação não convencional de palavras ${ }^{8}$. Tais índices nos permitiram observar os tipos de segmentações não convencionais de palavras mais recorrentes, as frequências e as dispersões das ocorrências de segmentações não convencionais de palavras identificadas nos textos das crianças antes e após o trabalho que realizamos.

No conjunto dos 78 textos analisados, identificamos 143 dados que foram classificados em hipersegmentação, hipossegmentação e híbridos ou mesclas. Apresentamos, na Tabela 1, os índices de ocorrências por tipos de segmentação não convencional de palavras na escrita inicial e na reescrita.

8 Os índices de segmentação não convencional de palavras foram obtidos a partir da razão do número de ocorrências de segmentação não convencional de palavras pelo número de palavras de cada texto. 0 resultado foi multiplicado por 100 para que pudéssemos trabalhar com um menor número de casas decimais. 
Tabela 1. Variação dos índices de ocorrência por tipos de segmentação

\begin{tabular}{c|c|c}
\cline { 2 - 3 } & Escrita inicial & Reescrita \\
\hline Hipersegmentação & 1,179 & 1,354 \\
\hline Hipossegmentação & 3,245 & 1,995 \\
\hline Híbridos & 0,147 & 0,142 \\
\hline
\end{tabular}

Fonte: Elaboração própria

Ao considerarmos os tipos de ocorrências e os índices apresentados, identificamos que há: (i) aumento de hipersegmentações de palavras após as atividades realizadas em ambiente escolar; (ii) uma redução acentuada das ocorrências de hipossegmentação de palavras e (iii) pouca redução dos dados híbridos. Interpretamos que os resultados (ii) e (iii) demonstram um movimento na escrita das crianças em direção à escrita convencional de palavras, embora o efeito seja mais acentuado para as hipossegmentações. Contrastando esses dois resultados com o descrito em (i), interpretamos o aumento de hipersegmentação como um movimento que tipicamente é nomeado de hipercorreção. É possível que as crianças tenham passado a usar o branco que representa fronteiras de palavras buscando identificar as convenções ortográficas, mesmo onde não haja correspondência com palavras ortográficas. Esseaumento do índice de hipersegmentação não pode ser interpretado como resultado de análise da palavra, o que não é negativo necessariamente, uma vez que pode ser efeito de um trabalho epilinguístico (ABAURRE, 1988) da criança em relação à delimitação das fronteiras gráficas de palavras.

No Gráfico 1, apresentamos dados quantitativos acerca do movimento na escrita das crianças antes e após o trabalho com a poesia.

Gráfico 1. Distribuição dos índices de segmentações não convencionais de palavras

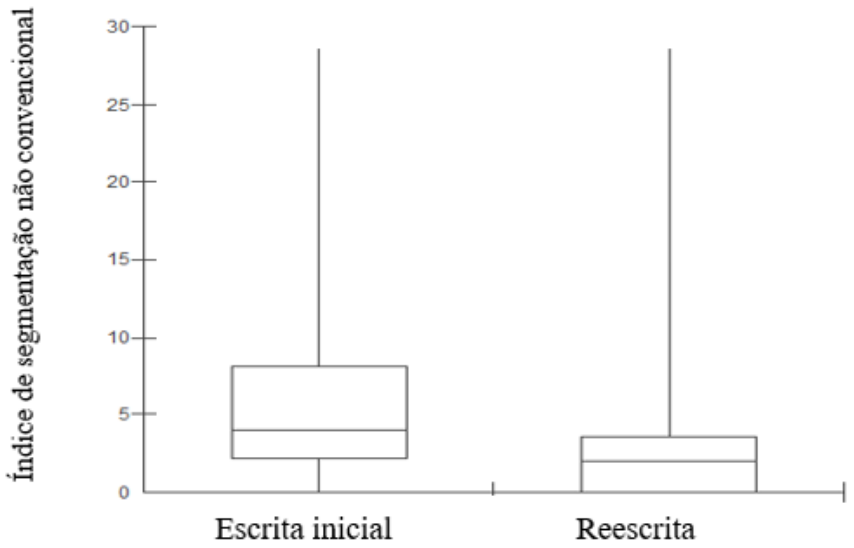

Fonte: Elaboração própria 
Identifica-se, no Gráfico 1, que a distribuição dos índices varia das escritas iniciais para as reescritas. Nas escritas iniciais, temos variabilidade maior de índices de ocorrências de segmentações não convencionais de palavras em relação aos índices de ocorrências nas reescritas e o índice mediano de ocorrências de segmentação não convencional de palavras praticamente foi reduzido pela metade do observado nos textos iniciais, passando de 4,00 para 2,00 aproximadamente. Interpretamos que o trabalho didático pedagógico realizado com os textos poéticos infantis gerou um maior número de palavras grafado convencionalmente; palavras que, anteriormente, foram segmentadas de modo não previsto pelas normas ortográficas passam ao registro convencional. A estatística descritiva, realizada por meio de teste Wilcoxon $(a=0,05)^{9}$, apresenta resultados que dão amparo para afirmar que há relevância do trabalho didático-pedagógico com textos poéticos infantis que destacam as segmentações alternativas de palavras de modo a levar as crianças a refletir sobre a ortografia dessas palavras.

Em relação à análise qualitativa quanto aos aspectos prosódicos dos enunciados, notouse que a estrutura recorrente nos dados de segmentação não convencionais de palavras foi de sequências constituídas de clítico e palavra prosódica, o chamado grupo clítico (GC) nas abordagens que seguem Nespor e Vogel (1986). Discutimos essa configuração a partir das Figuras 1 e 2, expostas a seguir.

Figura 1. Segmentação não convencional de palavra e grupo clítico

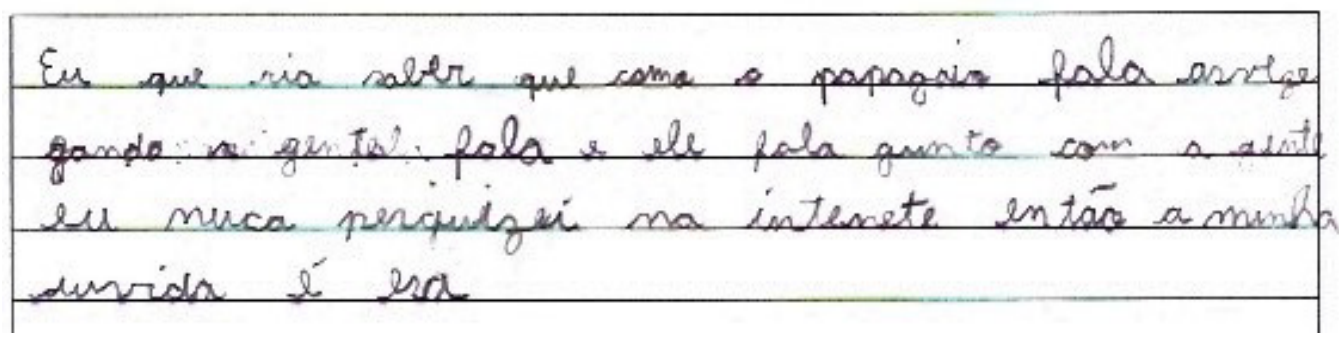

Fonte: JS18_3A_28M_110

$\mathrm{Na}$ Figura 1, ocorreram duas grafias não convencionais, especificamente, uma hipersegmentação, "que ria" (queria), e uma hipossegmentação, "asveze" (as vezes) ${ }^{11}$. A hipossegmentação envolve a estrutura prosódica de GC. Esta estrutura é composta

9 Utilizamos o software BioEstat 5.0 que se encontra disponível gratuitamente para realização das análises estatísticas.

10 Leitura possível: "Eu que ria saber que como o papagaio fala as veze gando a gente fala e ele fala gunto com a gente eu nuca pesquisei na internete então a minha duvida é esa.".

11 Observamos que os textos apresentam várias grafias não convencionais que dizem respeito à escolha de letra, concordância verbal e nominal. Sobre essas grafias não teceremos comentários, dados os objetivos deste artigo. 
por clítico (isto é, palavra átona), como "as", que é prosodicamente hospedado em uma palavra prosódica (isto é, uma palavra acentuada fonologicamente), como "vezes". A hipersegmentação compreende a presença do branco dentro da palavra de modo que, em "que ria" (queria), a fronteira de palavra empregada de modo não convencional resulta em duas palavras da língua, a saber: "que", uma conjunção subordinativa (que corresponde a um clítico predominantemente), e "ria", uma forma verbal do verbo "rir" (uma palavra prosódica). Chama-nos a atenção o fato de que este dado coloca em evidência possibilidades de sentido que são dadas pela ausência ou presença de fronteira de palavra numa mesma cadeia segmental, como exemplificamos a seguir. Da comparação entre os enunciados, verificamos, em (3), forma do verbo "rir" e, em (4), do verbo "querer", ou seja, mudaram os sentidos dos enunciados em uma ou outra segmentação.

(3) A menina que ria.

(4) A menina queria.

A grafia "asveze" (as vezes) constitui uma estrutura de grupo clítico. Nesse caso, um monossílabo átono é hipossegmentado a uma palavra acentuada. Essa estrutura já havia sido observada como recorrente nos textos das crianças e adolescentes, como observado por Tenani (2010) e Capristano (2007), esta, analisando grafias não convencionais em textos de alunos dos anos iniciais do EF, e aquela, analisando esse tipo de grafia em textos de alunos dos anos finais do EF.

Cientes da recorrência desse tipo de grafia que, em alguma medida, tem sua configuração ancorada na estrutura prosódica de clítico e seu hospedeiro, abordamos, durante as atividades realizadas a partir dos textos poéticos, segmentações alternativas de palavras que mobilizavam essas estruturas. De modo lúdico, por meio do material verbo-visual, lançamos mão de cores e de imagens para mostrarmos às crianças que há sílabas que ora podem fazer parte da palavra, ora podem estar separadas, como "em barco" > "embarco". Após essa atividade, o texto inicial foi reescrito. Na Figura 2, observamos que as palavras que antes foram grafadas de modo não convencional quanto à segmentação aparecem grafadas convencionalmente. 
Figura 2. Grafia de palavra e grupo clítico na reescrita

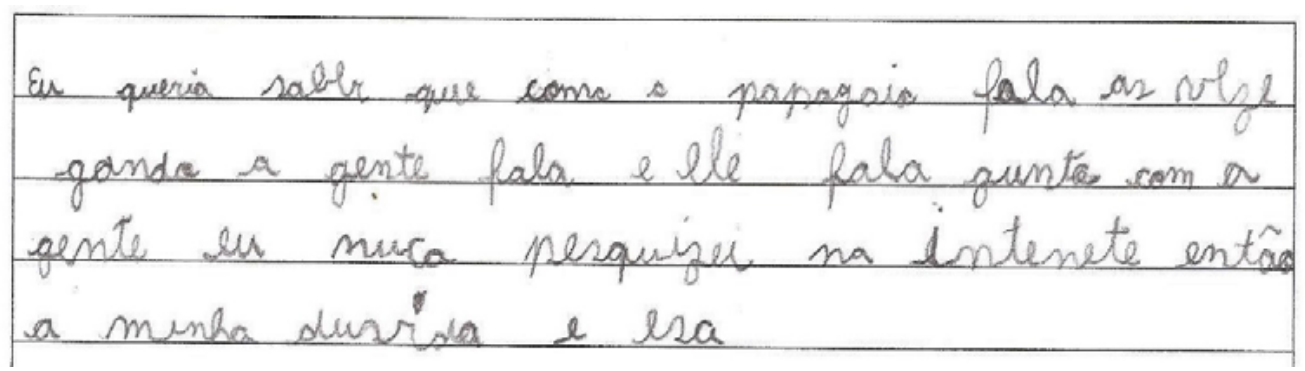

Fonte: JS18_3A_28M_212

A segunda estrutura prosódica que se mostrou mais mobilizada a partir da grafia de palavras foi a delimitação de palavra gráfica a partir de pés métricos $(\Sigma)$, como podemos observar nas Figuras 3 e 4.

Figura 3. Segmentação não convencional de palavra e pé métrico

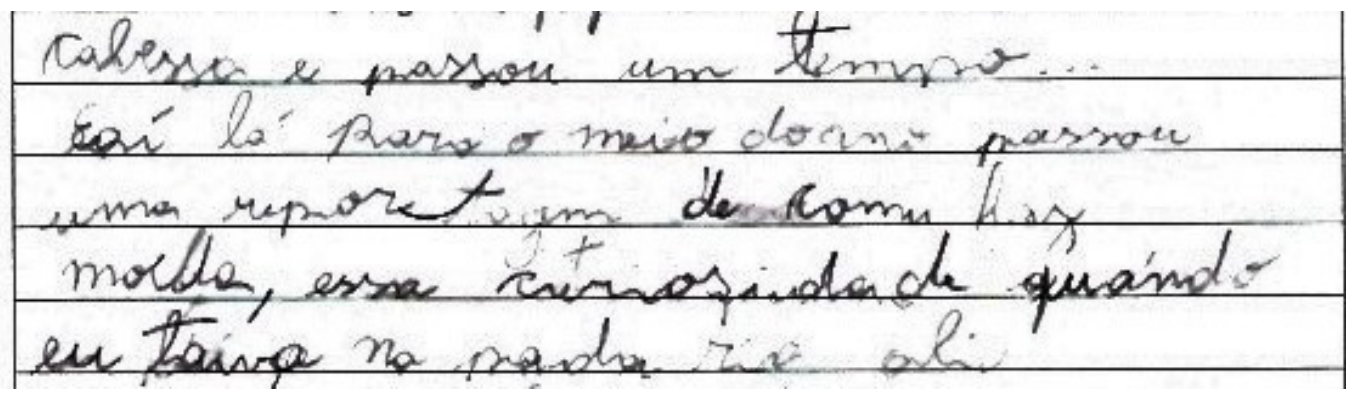

Fonte: JS18_3B_17F_173

Há, no texto ilustrado na Figura 3, uma ocorrência de hipersegmentação: "pada ria" (padaria). Esse dado permite-nos formular a hipótese de que o branco sinaliza limites de pés métricos, compostos pela sequência de uma sílaba forte e uma fraca. Segundo Bisol (2001), no português brasileiro, prevalece a forma de pés binários e de cabeça à esquerda, caracterizando o pé troqueu. No caso de "pada ria" (padaria), a grafia representa a sequência de dois pés trocaicos: "pada" e "ria". Chacon (2005), Abaurre (1991), Silva e Tenani (2014) trataram de hipersegmentações de palavras e observam a recorrência da configuração gráfica como sendo efeito da estrutura métrica mais recorrente na língua portuguesa: pés binários troqueus.

12 Leitura possível: "Eu queria saber que como o papagaio fala as veze gando a gente fala e ele fala gunto com a gente eu nuca pesquisei na internete então a minha duvida é esa.".

13 Leitura possível: "cabeça e passou um tempo... Eaí lá para o meio doano passou uma reportagem de como faz moeda, essa curiosidade quando eu tava na pada ria alí". 
Vale lembrar que os poemas infantis são textos privilegiados para abordar aspectos rítmicos que perpassam a escrita. A métrica dos poemas infantis que utilizamos na atividade em sala de aula mobiliza justamente a estrutura de pés binários trocaicos. Essa materialidade fônica foi trabalhada em sala de aula, a fim de que os alunos percebessem que, apesar de existir uma sílaba proeminente em relação às demais, esta proeminência fônica não é um critério suficiente para segmentar um vocábulo por meio do espaço em branco. Foi exatamente esta reflexão que promovemos nas atividades realizadas com os textos poéticos de Cecília Meireles. O vídeo, em especial, somado à leitura de alguns poemas, permitiu-nos exemplificar, para as crianças, a complexa relação entre o que falamos/ouvimos e o que escrevemos/lemos.

Após essa atividade sobre a escrita, foi feita a reescrita dos enunciados escritos. $\mathrm{Na}$ figura 4, podemos observar que a palavra "padaria", hipersegmentada na figura 3, passa a ser grafada convencionalmente.

Figura 4. Grafia de palavra e pés métricos na reescrita

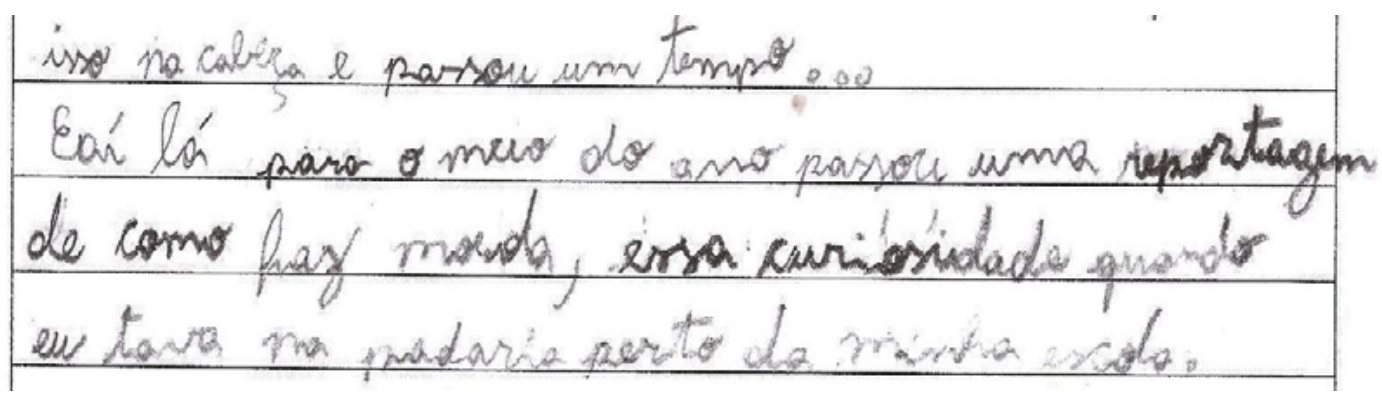

Fonte: JS18_3B_17F_2 ${ }^{14}$

Ao compararmos os textos nas Figuras 3 e 4, notamos que, além da segmentação não convencional "pada ria" (padaria), algumas grafias apresentam marcas de apagamentos e traços que, como anunciamos na introdução deste artigo, assumimos como marcas do trabalho das crianças, enquanto sujeitos da linguagem, com as fronteiras das palavras e, especialmente, com os possíveis sentidos dos enunciados escritos. Por esse motivo, nos debruçamos sobre esses dados, a fim de argumentar que esses também nos permitem investigar as hipóteses elaboradas pela criança ao segmentar palavras. Na próxima seção, tratamos das informações verbo-visuais relevantes para a construção de palavras pelas crianças no EF.

14 Leitura possível: "isso na cabeça e passou um tempo... Eaí lá para o meio do ano passou uma reportagem de como faz moeda, essa curiosidade quando eu tava na padaria perto da minha escola.". 


\section{"Mas não consegui escolher ainda qual é melhor: se é isto ou aquilo": particularidades dos aspectos gráficos da escrita de palavras}

Na terceira linha do texto na Figura 3, há a grafia de um longo traço, saindo da letra "t", entre as grafias de "repor" e "tagem" (reportagem). É possível que, num primeiro momento, tenha sido produzida uma hipersegmentação que, logo em seguida foi "corrigida" pela criança, com a tentativa de unir, por meio do traço da letra " $t$ ", uma parte da palavra a outra. Interessante é que ambas as partes da palavra configuram-se em pés trocaicos. Não podemos descartar a hipótese de que esta criança ainda está em dúvidas sobre os critérios para segmentar palavras ao grafar palavras que formam pés métricos trocaicos. Elaboramos essa hipótese levando em conta ainda que, no mesmo texto, aparece palavra hipersegmentada em limites de pés trocaicos. Na Figura 4, a palavra "reportagem" aparece convencionalmente e sem traços, porém, verifica-se que a criança reforça com o lápis a grafia, como um possível indício ao leitor de que a dúvida da primeira grafia foi, na segunda produção, resolvida. Esclarecemos que entendemos esses registros gráficos como efeitos do trabalho do sujeito da linguagem com a escrita, tendo por base possibilidades da língua de organização do enunciado.

Ainda na terceira linha do texto na Figura 3, identifica-se que, logo em seguida à palavra "reportagem", há marcas de apagamentos na grafia de "de como". O apagamento ocorre entre o clítico "de", uma preposição, e a palavra fonológica "como", uma conjunção. É possível que a criança tenha hesitado ao grafar um monossílabo átono que, noutras vezes, na língua portuguesa, pode funcionar como sílaba de uma palavra ortográfica. Interpretamos que esta marca de apagamento pode indiciar as hipóteses que a criança elaborou a partir do conhecimento ortográfico advindo de práticas sociais letradas. Na reescrita, não encontramos marcas de apagamento ao observarmos a grafia de "de como", como se verifica no texto na Figura 4, e, mais uma vez, a criança parece ter buscado reforçar a grafia que produz, evidenciando ao leitor, no caso a pesquisadora, que buscou alçar sua escrita à convenção ortográfica.

\section{Considerações finais}

Nesse estudo, tratamos de possibilidade de ensino de ortografia nos anos iniciais do ensino fundamental a partir de trabalho didático pedagógico com poemas infantis de autoria de Cecília Meireles, selecionados da obra Ou isto ou Aquilo, e que tinham a característica comum de haver segmentações alternativas de palavra.

Em relação ao nosso objetivo de analisar quantitativamente segmentações não convencionais de palavras nas produções textuais de crianças, antes e depois do trabalho com textos poéticos infantis, verificamos que, de modo geral, os índices de segmentações não convencionais de palavras diminuíram, mostrando, assim, que houve efeito positivo do trabalho didático pedagógico na escrita das crianças. Ponderamos 
que não foi possível testar se outro tipo de atividade sobre segmentação de palavras, baseada em textos que não sejam de natureza poética, teria resultado semelhante aos ora relatados junto aos alunos do terceiro ano do Ensino Fundamental. De todo modo, o teste estatístico dá amparo para afırmar que houve redução de segmentações não convencionais de palavras após o trabalho realizado. Interpretamos que esses resultados sugerem a relevância da proposta ora descrita para a aprendizagem de delimitar fronteiras de palavras convencionalmente.

Ao que tange ao nosso objetivo de analisar qualitativamente segmentações não convencionais de palavras, observamos que a estrutura mais recorrente das segmentações não convencionais de palavras corresponde à sequência de clítico e palavra prosódica, seguida de grafias que correspondem a pés métricos. Verificou-se também que características prosódicas estão presentes nas segmentações alternativas de palavras identificadas nos poemas de Meireles por Alves (2017). Essa relação entre ambos os tipos de dados mostra-se relevante para o trabalho entre fala e escrita e, ainda, para o ensino de ortografia nos anos iniciais do EF, uma vez que favorece a reflexão metalinguística por parte da criança sobre a atividade de representar o enunciado em palavras a partir de características não apenas da fala, mas também dos sentidos no enunciado escrito.

\section{REFERÊNCIAS}

ABAURRE, M. B. M. A relevância dos critérios prosódicos e semânticos na elaboração de hipóteses sobre segmentação na escrita inicial. Boletim da Abralin, Campinas, v. 11, p. 203-217, 1991.

ABAURRE, M. B. M. Hipóteses iniciais de escrita: evidências da percepção por préescolares, de unidades rítmico/entoacionais na fala. Anais do IV Encontro Nacional da ANPOL, p. 1-15, 1989.

ABAURRE, M. B. M. O que revelam os textos espontâneos sobre a representação que faz a criança do objeto escrito? In: KATO, M. A. (org.). A concepção da escrita pela criança. v. 1. 2. ed. Campinas: Pontes, 1988. p. 135-142.

ABAURRE, M. B. M.; CAGLIARI, L. C. Textos espontâneos na primeira série: evidências da utilização, pela criança, de sua percepção fonética da fala para representar e segmentar a escrita. Cadernos CEDES - Antropologia e Educação Interfaces do Ensino e da Pesquisa, São Paulo, v. 14, p. 25-29, 1985.

ABAURRE, M. B. M.; SILVA, A. O desenvolvimento de critérios de segmentação na escrita. Temas em psicologia. São Paulo, v. 1, p. 89-102, 1993. 
ABRAMOVICH, F. Literatura infantil: gostosuras e bobices. São Paulo: Scipione, 1997.

ALVES, G. Textos poéticos e ensino de ortografia: Cecília Meireles, empresta o versinho? 2018. Trabalho de Conclusão de Curso (Graduação em Letras) - Instituto de Biociências, Letras e Ciências Exatas, Universidade Estadual Paulista, São José do Rio Preto, 2018.

AUTHIER-REVUZ, J. Duas ou três coisas sobre as relações da Língua com o que ela não é. In: AUTHIER-REVUZ, J. Palavras incertas; as não coincidências do dizer. Campinas: Editora da UNICAMP, 1998. p. 165-175.

BISOL, L. Os constituintes prosódicos. In: BISOL. L. (org.). Introdução a estudos de fonologia do português brasileiro. 3. ed. Porto alegre: EDIPUCRS, 2001. p. 229-241.

BRASIL. Ministério da Educação. Secretaria de Educação Básica. Diretoria de Apoio à Gestão Educacional. Pacto Nacional pela Alfabetização na Idade Certa: Formação do professor alfabetizador: Caderno de Apresentação. Brasília: MEC/SEB, 2012.

BRASIL. Ministério da Educação. Secretaria de Educação Básica. Diretoria de Apoio à Gestão Educacional. Pacto Nacional pela Alfabetização na Idade Certa: A oralidade, a leitura e a escrita no ciclo de Alfabetização: Caderno 5. Brasília: MEC/SEB, 2015.

CAPRISTANO, C. C. Segmentação na escrita infantil. São Paulo: Martins Fontes, 2007.

CAPRISTANO, C. C. A propósito da escrita infantil: uma reflexão sobre as segmentações não convencionais. Letras de Hoje, Porto Alegre, v. 39, n. 3, p. 245-260, 2004.

CHACON, L. Hipersegmentações na escrita infantil: entrelaçamento de práticas de oralidade e de letramento. Estudos Linguísticos, Campinas, v. 34, p. 77-86, 2005.

CHACON, L. Constituintes prosódicos e letramento em segmentações nãoconvencionais. Letras de Hoje, Porto Alegre, v. 39, n. 3, p. 223-232, 2004.

CORRÊA, M. L. G. O modo heterogêneo de constituição da escrita. São Paulo: Martins Fontes, 2004.

CUNHA, A. P. N. As segmentações não-convencionais da escrita inicial: uma discussão do ritmo linguístico do português brasileiro e europeu. 2010. Tese (Doutorado em Educação) - Faculdade de Educação, Universidade Federal de Pelotas, Pelotas, 2010. 
MARQUEZI, R. A. Um estudo sobre poemas de "Ou Isto ou Aquilo" de Cecilia Meireles. 2000. Dissertação (Mestrado em Educação) - Faculdade de Filosofia e Ciências, Universidade Estadual Paulista "Júlio de Mesquita Filho", Marília, 2000.

MEIRELES, C. Ou Isto ou Aquilo. 7. ed. São Paulo: Global. 2014.

NESPOR, M.; VOGEL, I. Prosodic phonology. Dordrechet: Foris Publications, 1986.

SILVA, L. M.; TENANI, L. Hipersegmentações de palavras no Ensino Fundamental. São Paulo: Cultura Acadêmica, 2014.

TENANI, L. Prosódia e escrita: uma análise a partir de (hiper)segmentações de palavra. 2016. Tese (Livre Docência) - Instituto de Biociências, Letras e Ciências Exatas, Universidade Estadual Paulista "Júlio de Mesquita Filho", São José do Rio Preto, 2016.

TENANI, L. A grafia dos erros de segmentação não-convencional de palavras. Cadernos de Educação, Pelotas, p. 247-269, jan./abr. 2010.

TENANI, L. Rindo das piadas, manipulando a língua. Alfa (UNESP), São Paulo, v. 45, p. 115-127, 2001.

ZILBERMAN, R. Como e por que ler a literatura infantil brasileira. São Paulo: Objetiva, 2005. 